Check for updates

Cite this: RSC Adv., 2018, 8, 15001

Received 20th December 2017

Accepted 2nd April 2018

DOI: 10.1039/c7ra13502e

rsc.li/rsc-advances

\section{Antimicrobial and optical properties of PET chemically modified and grafted with borane compounds}

\author{
Monika Benkocká, (D) *a Simona Lupínková, ${ }^{2}$ Jindřich Matoušek, ${ }^{a}$ Kateřina Kolářováb \\ and Zdeňka Kolskáa
}

Polyethylene terephthalate (PET) foils were activated with piranha solution and grafted with selected amino compounds (cysteamine, ethylenediamine or chitosan) and then with borane compounds. Changes in their surface properties after particular modification steps were examined using electrokinetic analysis, X-ray photoelectron spectroscopy (XPS), goniometry and UV-vis spectroscopy. Several tests showed that the presence of some amino compounds and one borane cluster significantly improved the antimicrobial properties of the composites investigated. In particular, they exhibited strong antibacterial activity against Staphylococcus epidermidis but only weak activity against Escherichia coli. The samples modified with amino compounds and subsequently with borane clusters were luminescent under UV lamp irradiation. Therefore, the nanocomposites consisting of (cheap) polymer and (more expensive) borane could be used in luminophore development, medicine or environmental protection.

\section{Introduction}

Polymeric materials, for example polyethylene terephthalate (PET), have replaced most of the traditional engineering materials, such as steel and aluminium, and partially replaced those used in biomedical applications. This is due to their excellent properties, in particular, their better corrosion resistance, low density, flexibility, low cost, availability and ease of recycling. ${ }^{1-4}$ However, their surface properties like wettability, biocompatibility or poor adhesion to other materials, chemicals, microorganisms, etc. significantly limit their use in some cases. To avoid these deficiencies, polymer surfaces can be modified without the loss of their excellent bulk properties. Polymer surfaces can be modified by chemical methods (wet processes using only chemical substances ${ }^{5-7}$ ), physical methods like plasma treatment, ${ }^{8-11} \mathrm{UV}$ irradiation ${ }^{12-14}$ or combinations of both physical and chemical methods. ${ }^{15,16}$ Each of them has advantages and disadvantages. Wet methods make use of corrosive liquids, like piranha solution (a mixture of an acid or alkali with hydrogen peroxide), potassium permanganate and nitric acid. ${ }^{17-21}$ The effect of these chemical methods is the creation of reactive oxygenized functional groups on the polymer surface. ${ }^{18,21}$ Physical methods are not as cheap and easily available, since they use more complicated and expensive

${ }^{a}$ Faculty of Science, J. E. Purkinje University in Usti nad Labem, České Mládeže 8, 400 96 Usti nad Labem, Czech Republic. E-mail: BenkockaMonika@seznam.cz; mbenkocka@gmail.com

${ }^{b}$ Institute of Solid State Engineering, University of Chemistry and Technology Prague, Technická 5, 16628 Prague 6, Czech Republic technical equipment, but on the other hand they do not produce harmful waste. ${ }^{17}$ In fact, they are more widely used for polymer modification.

Boranes are stable compounds consisting of boron and hydrogen. They create three-dimensional clusters with many interesting and important properties, such as high fluorescence yield $^{22}$ and the production of singlet oxygen. ${ }^{23}$ Singlet oxygen can be used in photodynamic therapy, in photomedicine for cancer treatment $\mathrm{t}^{24-26}$ or for uses connected with its antimicrobial effects. ${ }^{27,28}$ Fluorescence can be used in chemical sensors (fluorescence spectroscopy), ${ }^{29,30}$ fluorescent dyes ${ }^{31,32}$ or biological detectors. ${ }^{33}$ However, borane synthesis is difficult and borane compounds are quite expensive. The successful grafting of expensive boranes on cheap common polymers paves the way for the creation of new materials based on polymer/borane nanocomposites, combining the excellent and important properties of both components and significantly reducing the amount of expensive boranes.

In this work, the surface of polyethylene terephthalate (PET) foil was chemically activated to improve its surface properties for the subsequent grafting with borane compounds. The whole procedure and the changes in the physico-chemical properties of the activated and grafted polymer surface were monitored using different analytical techniques. It was confirmed that boranes deposited on the polymer surface preserve their original properties (their antimicrobial effect and luminescence yield). Polymer/borane nanocomposites exhibit pronounced luminescence and antimicrobial properties and they could be used in luminophore development and/or medical applications. 


\section{Results and discussion}

The most important surface properties were determined before and after each individual step of surface activation and subsequent chemical modification. In total, 13 different samples in different activation and chemical modification phases were examined. The samples, marked by specific abbreviations, are listed in Table 1.

Below, the results of the different analyses are presented, which confirm the successful modification of the PE surface and grafting with amino compounds and/or borane clusters.

Electrokinetic analysis is an easy, fast and sensitive method which can indicate even very small changes in surface chemistry and charge, before and after any surface modification. The obtained zeta potential values for all samples of unmodified or modified PET foils are presented in Fig. 1. As we can see, after activation with piranha solution (PET-2) there are changes in the surface chemistry and charge in comparison with unmodified PET (PET-1), due to the creation of new reactive sites and polar groups on the surface. Polar groups created on the surface after surface activation facilitate the subsequent grafting of other tested chemical compounds. The grafting of amino compounds (cysteamine, ethylenediamine or chitosan) results in a "less negative" zeta potential (PET-5,8,11) in all cases, due to the presence of amino groups on the surface. ${ }^{5,16,34}$ In the case of chitosan, this change is more significant because it is a larger molecule and a larger number of amino groups are deposited on the surface. Molecules of borane compounds have a slightly negative charge, so grafting with selected borane compounds leads to more negative values of zeta potential (PET$3,4,6,7,9,10)$. This is clear, especially after grafting with B2, where the effect is due to thiol groups in the molecule which create a negative surface charge in the presence of the $\mathrm{KCl}$ water solution, leading to a more negative zeta potential. ${ }^{16}$ These results confirmed the successful surface activation and chemical grafting of all tested chemical compounds.

The borane compound anti- $\mathrm{B}_{18} \mathrm{H}_{22}, \mathrm{~B} 1$, shows pronounced luminescence and photophysical properties. ${ }^{22,34}$ Our goal was to prove that the luminescence properties of borane are preserved after borane grafting on a polymer surface. This new composite with luminescence activity could help prepare luminophore

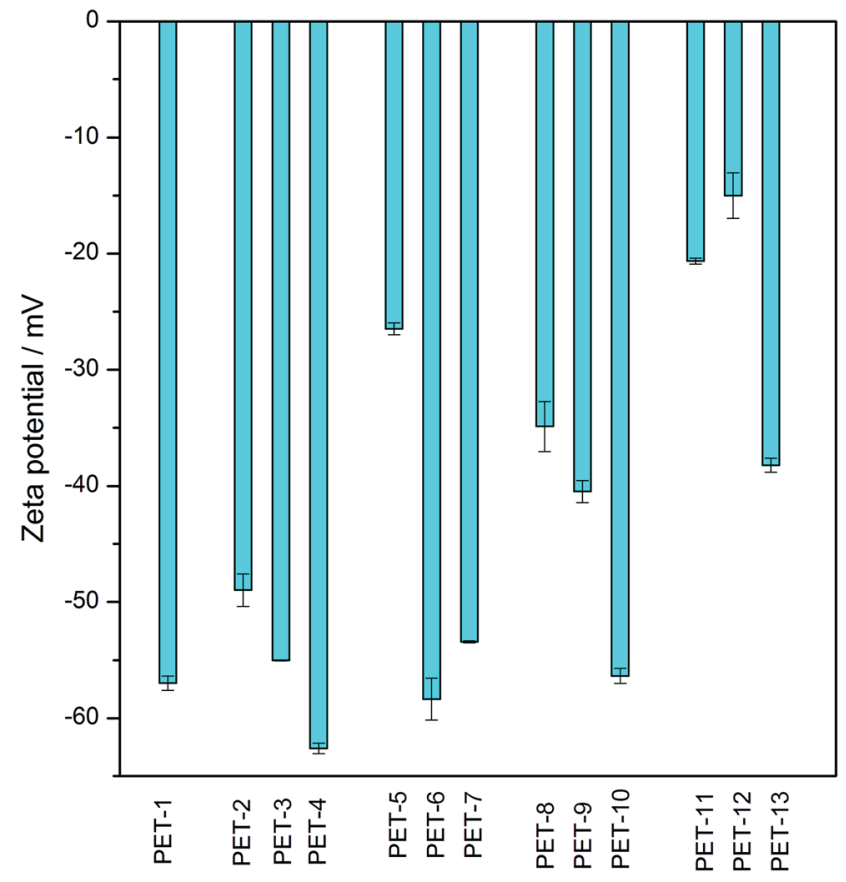

Fig. 1 The electrokinetic potential of PET foil: pristine (PET-1), activated in piranha solution (PET-2) and grafted with amino compounds (cysteamine, PET-5; ethylenediamine, PET-8; chitosan, PET-11) and subsequently with tested borane compounds, anti- $\mathrm{B}_{18} \mathrm{H}_{22}$ (PET$3,6,9,12)$ or $4,4^{\prime}-(\mathrm{HS})_{2}-$ anti- $\mathrm{B}_{18} \mathrm{H}_{20}$ (PET-4,7,10,13).

materials on the basis of polymer/borane composites. In this sense, the present study is a continuation of our previous one on silicates. ${ }^{34}$ Our samples and their behaviour under UV lamp irradiation (365 nm) can be seen in Fig. 2. One can see that the samples modified with the luminescent borane compound anti$\mathrm{B}_{18} \mathrm{H}_{22}$ (B1, third line of Fig. 2 and PET-3,6,9,12) exhibit luminescence and photo-physical properties. These results confirmed (i) the successful B1 grafting of the PET foil surface and (ii) the preservation of the photo-physical properties of B1, even after its grafting on the PET substrate. This work opens the door to the development of new stable low-cost nanocomposite materials with extraordinary properties.

Table 1 Sample survey

PET-1

PET-2

PET-3

PET-4

PET-5

PET-6

PET-7

PET-8

PET-9

PET-10

PET-11

PET-12

PET-13
Pristine (unmodified) PET foil

PET foil activated by piranha solution

PET foil activated by piranha solution and grafted with anti- $\mathrm{B}_{18} \mathrm{H}_{22}$ (B1)

PET foil activated by piranha solution and grafted with $4,4^{\prime}-(\mathrm{HS})_{2}$-anti- $\mathrm{B}_{18} \mathrm{H}_{20}(\mathrm{~B} 2)$

PET foil activated by piranha solution and grafted with cysteamine

PET foil activated by piranha solution and grafted with cysteamine and subsequently with anti- $\mathrm{B}_{18} \mathrm{H}_{22}(\mathrm{~B} 1)$

PET foil activated by piranha solution and grafted with cysteamine and subsequently with $4,4^{\prime}-(\mathrm{HS})_{2}-$ anti- $\mathrm{B}_{18} \mathrm{H}_{20}(\mathrm{~B} 2)$

PET foil activated by piranha solution and grafted with ethylenediamine

PET foil activated by piranha solution and grafted with ethylenediamine and subsequently with anti- $\mathrm{B}_{18} \mathrm{H}_{22}(\mathrm{~B} 1)$

PET foil activated by piranha solution and grafted with ethylenediamine and subsequently with $4,4^{\prime}-(\mathrm{HS})_{2}-$ anti- $\mathrm{B}_{18} \mathrm{H}_{20}(\mathrm{~B} 2)$

PET foil activated by piranha solution and grafted with chitosan

PET foil activated by piranha solution and grafted with chitosan and subsequently with anti- $\mathrm{B}_{18} \mathrm{H}_{22}(\mathrm{~B} 1)$

PET foil activated by piranha solution and grafted with chitosan and subsequently with $4,4^{\prime}-\left(\mathrm{HS}_{2}\right)_{2}$-anti- $\mathrm{B}_{18} \mathrm{H}_{20}(\mathrm{~B} 2)$ 


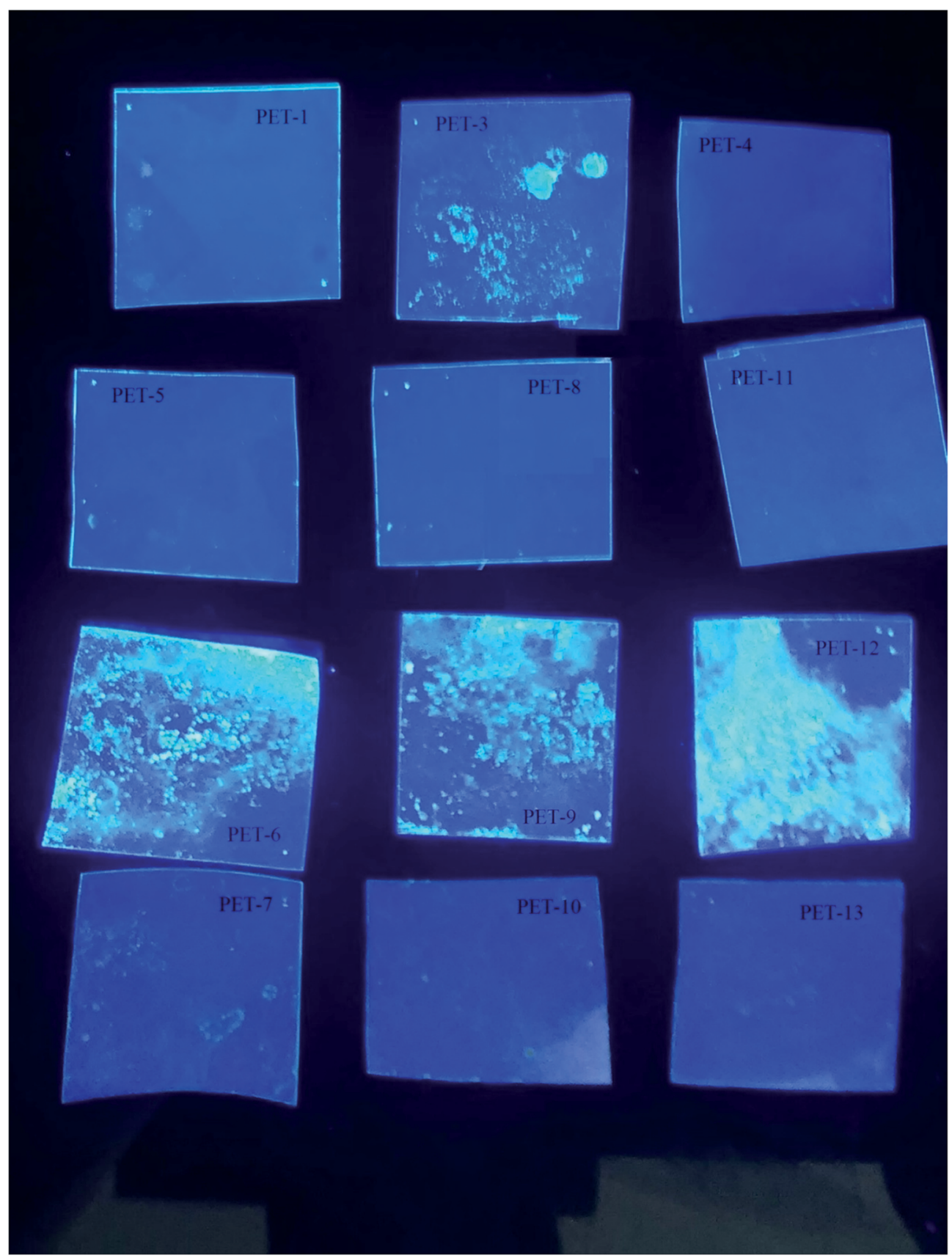

Fig. 2 PET foils under UV lamp irradiation (365 nm). First row (from left to right): pristine PET (PET-1), PET activated by piranha solution consisting of $\mathrm{CH}_{3} \mathrm{COOH}$ and subsequently grafted with anti- $\mathrm{B}_{18} \mathrm{H}_{22}$ (B1, PET-3) or 4,4'-(HS) $)_{2}$-anti- $\mathrm{B}_{18} \mathrm{H}_{20}$ (B2, PET-4); second row: PET activated by piranha solution and grafted with cysteamine (PET-5), diamine (PET-6) or chitosan (PET-7); third row: PET activated by piranha solution and grafted with cysteamine, diamine or chitosan and subsequently with anti- $\mathrm{B}_{18} \mathrm{H}_{22}$ (B1, PET-6,9,12); fourth row: PET activated by piranha solution and grafted with cysteamine, diamine or chitosan and subsequently with $4,4^{\prime}-(\mathrm{HS})_{2}-a n t i-\mathrm{B}_{18} \mathrm{H}_{20}(\mathrm{~B} 2, \mathrm{PET}-7,10,13)$.

UV-vis spectra were measured on PET foil activated by piranha solution and grafted with amino compounds and subsequently with anti- $\mathrm{B}_{18} \mathrm{H}_{22}$ (B1), with the aim of confirming fluorescence activity. Typical UV-vis spectra taken at $\lambda=380 \mathrm{~nm}$ are shown in Fig. 3. While pristine PET foil (PET-1, green dashed line) shows no fluorescence activity, PET treated in piranha solution and grafted with cysteamine and subsequently with anti- $\mathrm{B}_{18} \mathrm{H}_{22}$ (B1, PET-6, red dashed-dot line) exhibits obvious fluorescence activity. For comparison, the fluorescence of original highly fluorescent anti- $\mathrm{B}_{18} \mathrm{H}_{22}$ (B1, black line) is also shown.

The activation and subsequent grafting of selected amino compounds and borane compounds led to significant changes in surface wettability in comparison with pristine PET foil. Surface hydrophobicity or hydrophilicity are known to play a crucial role in surface adhesion or cytocompatibility. ${ }^{16,35,36}$ The difference in surface wettability between pristine PET and PET foil after activation with piranha solution, grafting with 


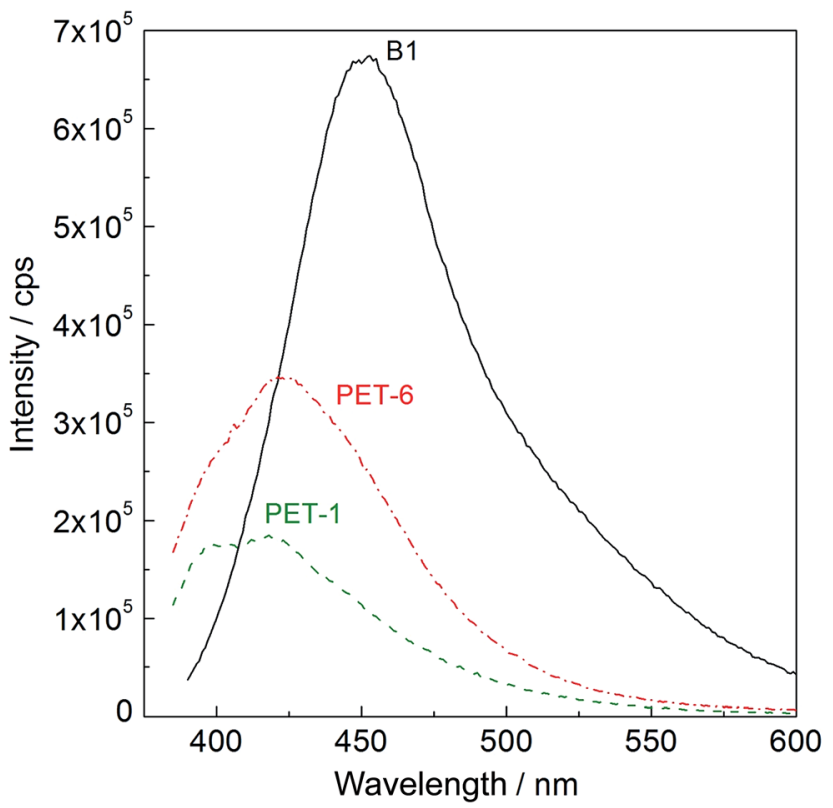

Fig. 3 UV-vis spectra (at $380 \mathrm{~nm}$ ) of the original borane compound anti- $\mathrm{B}_{18} \mathrm{H}_{22}$ (B1, black solid line), pristine PET foil (PET-1, green dashed line) and PET foil after activation with piranha solution and grafting with cysteamine and subsequently with B1 (PET-6, red dashed-dot line).

cysteamine and subsequent grafting with B1 is illustrated in Fig. 4. The contact angles measured on all studied samples are summarized in Table 2.

The chemical composition of the PET surface before and after activation and subsequent grafting of selected compounds was determined using XPS. The results confirm changes in the surface chemistry after the individual steps of surface activation and subsequent chemical grafting. Table 3 summarizes the results for pristine PET foil (PET-1) and foil activated by piranha solution (PET-2), subsequently grafted with amino compounds (cysteamine, PET-5; ethylenediamine, PET-8; or chitosan, PET11) and subsequently grafted with both borane compounds (B1, PET-6,9,12 or B2, PET-7,10,13). On pristine PET foil (PET-1), only $\mathrm{C}$ and $\mathrm{O}$ atoms are visible. After piranha activation (PET-2), the concentration of $\mathrm{O}$ increases slightly due to the presence of oxygen-containing polar groups from the piranha solution. An increase in $\mathrm{N}$ concentration confirms the successful grafting of all of the tested amino compounds (PET-5-PET-13). The presence of $\mathrm{B}$ on the surface confirms the successful grafting of the borane compounds (PET-3,4,6,7,9,10,12,13). In the case of
Table 2 Contact angles of pristine PET foil (PET-1) and PET foil after activation with piranha solution (PET-2) and grafting with selected amino compounds (cysteamine, ethylenediamine or chitosan, PET$5,8,11$ ) and subsequently with borane compounds (B1, PET-6,9,12 or B2, PET-7,10,13)

\begin{tabular}{llll}
\hline Sample & Contact angle $\left[^{\circ}\right]$ & Sample & Contact angle $\left[^{\circ}\right]$ \\
\hline PET-1 & $72.9 \pm 1.1$ & PET-8 & $60.6 \pm 1.7$ \\
PET-2 & $76.6 \pm 2.6$ & PET-9 & $61.8 \pm 1.5$ \\
PET-3 & $69.9 \pm 1.9$ & PET-10 & $75.9 \pm 1.9$ \\
PET-4 & $73.7 \pm 0.9$ & PET-11 & $53.6 \pm 1.8$ \\
PET-5 & $62.8 \pm 1.7$ & PET-12 & $70.1 \pm 2.3$ \\
PET-6 & $57.1 \pm 1.6$ & PET-13 & $84.5 \pm 2.5$ \\
PET-7 & $77.1 \pm 2.3$ & & \\
\end{tabular}

Table 3 Elemental composition in at\% for PET foils, as determined using XPS. Pristine PET foil (PET-1), foil activated by piranha solution (PET-2) and subsequently grafted with borane compounds B1 (PET-3) or B2 (PET-4) and foil activated by piranha solution and subsequently grafted with amino compounds (cysteamine, PET-5; ethylenediamine, PET-8; or chitosan, PET-11), then subsequently grafted with both tested borane compounds (B1, PET-6,9,12 or B2, PET-7,10,13)

\begin{tabular}{llllll}
\hline & $\mathrm{C}(1 \mathrm{~s})$ & $\mathrm{O}(1 \mathrm{~s})$ & $\mathrm{B}(1 \mathrm{~s})$ & $\mathrm{N}(1 \mathrm{~s})$ & $\mathrm{S}(2 \mathrm{p})$ \\
\hline PET-1 & 73.0 & 27.0 & - & - & - \\
PET-2 & 71.0 & 29.0 & - & - & - \\
PET-3 & 66.9 & 26.0 & 7.1 & - & - \\
PET-4 & 69.0 & 22.3 & 5.0 & - & 3.7 \\
PET-5 & 74.3 & 24 & - & 1.1 & 0.6 \\
PET-6 & 71 & 18.5 & 9.4 & 0.6 & 0.5 \\
PET-7 & 71 & 19 & 7.1 & 0.5 & 2.4 \\
PET-8 & 70.5 & 27 & - & 2.5 & - \\
PET-9 & 65.6 & 22 & 10.4 & 2.0 & - \\
PET-10 & 68 & 25 & 4.8 & 1.3 & 0.9 \\
PET-11 & 69.2 & 29.2 & - & 1.6 & - \\
PET-12 & 65.0 & 20.2 & 13.6 & 1.2 & - \\
PET-13 & 66.4 & 20.2 & 8.8 & 1.2 & 3.4 \\
& & & & & \\
\hline
\end{tabular}

thiolated borane B2 (PET-4,7,10,13), S on the sample surface is also observed. All of these results confirm the successful modification steps of the PET surface, including borane compound grafting after the first activation step with piranha solution (without the grafting of amino compounds as "conjunction"). On the other hand, the amount of grafted borane compounds was found to increase after pre-grafting with any tested amino compounds. These results were also confirmed using other techniques.

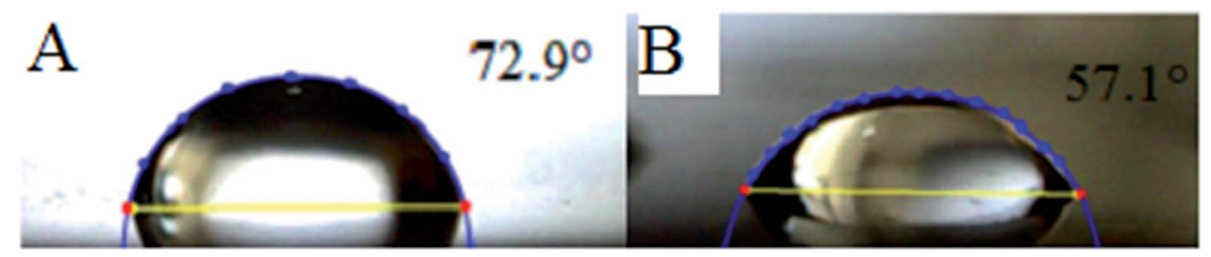

Fig. 4 Contact angles of pristine PET foil (A) and PET foil after activation with piranha solution and grafting with cysteamine and subsequently with B1 (B). 


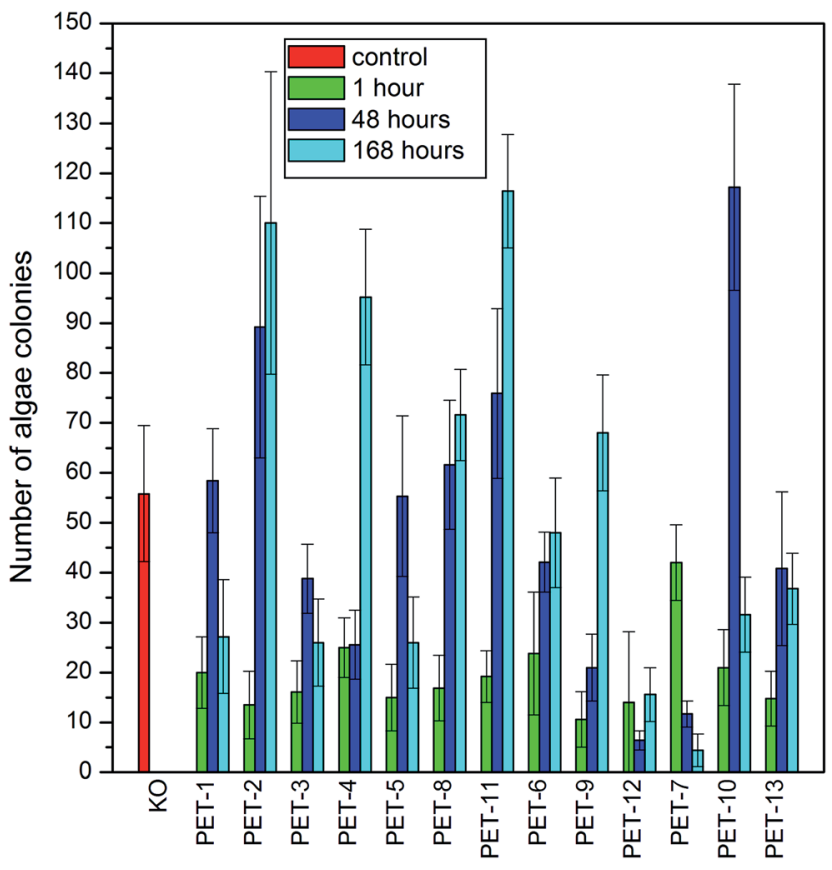

Fig. 5 The growth inhibition of Desmodesmus quadricauda algae of samples of pristine PET foil (PET-1) and after activation and chemical modification: after piranha solution (PET-2), after subsequent grafting of the tested amino compounds (PET-5,8,11) and subsequent grafting of the tested borane compounds, B1 or B2 (PET-6,7,9,10,12,13).

The aim of this study was to verify that all of the excellent properties of the original borane compounds, including their antimicrobial activity, are preserved after grafting on modified PET surfaces. For this purpose, (i) a test on the inhibition of algae growth and (ii) an antibacterial test on Gram-negative and Gram-positive bacteria were performed using PET foils before and after surface activation and individual chemical modifications.
First, the algae growth inhibition tests were carried out on all studied samples. The results are presented in Fig. 5. It is clear that PET modified with chitosan and B1 or B2 showed only weak antibacterial activity against Desmodesmus quadricauda algae in comparison with the control (KO) and with pristine PET foil (PET-1), which was especially visible after 7 days. As could be expected, the presence of amino groups on the surface resulted in better cell adhesion which played a key role in cell proliferation. ${ }^{16,37,38}$ On the other hand, the presence of borane compounds reduced algae growth strongly on all samples. The results of these tests confirm that grafted boranes preserve their antimicrobial activity.

The second antimicrobial test, the study of antibacterial activity on Gram-negative and Gram-positive bacteria, was carried out for all samples. The results for $S$. epidermidis (A) and E. coli (B) are presented in Fig. 6. Since $S$. epidermidis has a significantly lower CFU in comparison with $E$. coli, different amounts of both bacteria were added to the samples in accord with the results of previous experiments. ${ }^{16,38}$ A greater amount of $S$. epidermidis bacteria was added to the bacterial suspension since it shows weaker (slower) growth and higher sensitivity (so even less and worse proliferation) in comparison with $E$. coli. ${ }^{37}$ The results presented in Fig. 6A and B confirmed the antibacterial activity of surfaces grafted with B1 or B2. Interesting results were obtained for a chitosan combination (PET-12,13). In the case of $S$. epidermidis (Fig. 6A), all samples grafted with amino compounds and subsequently with B1 (PET-6,9,12) and also for B2 pre-grafted with chitosan (PET-13) show significant antibacterial behaviour. Only a small amount of antibacterial activity for the PET foil grafted with B1 and B2 pre-grafted with chitosan for $E$. coli, in comparison with other tested samples, was observed. The strong resistance of $E$. coli against many agents is well known. ${ }^{37,39}$ As could be expected, the presence of amino compounds on a surface resulted in better cell adhesion, which has been demonstrated previously. It has been found
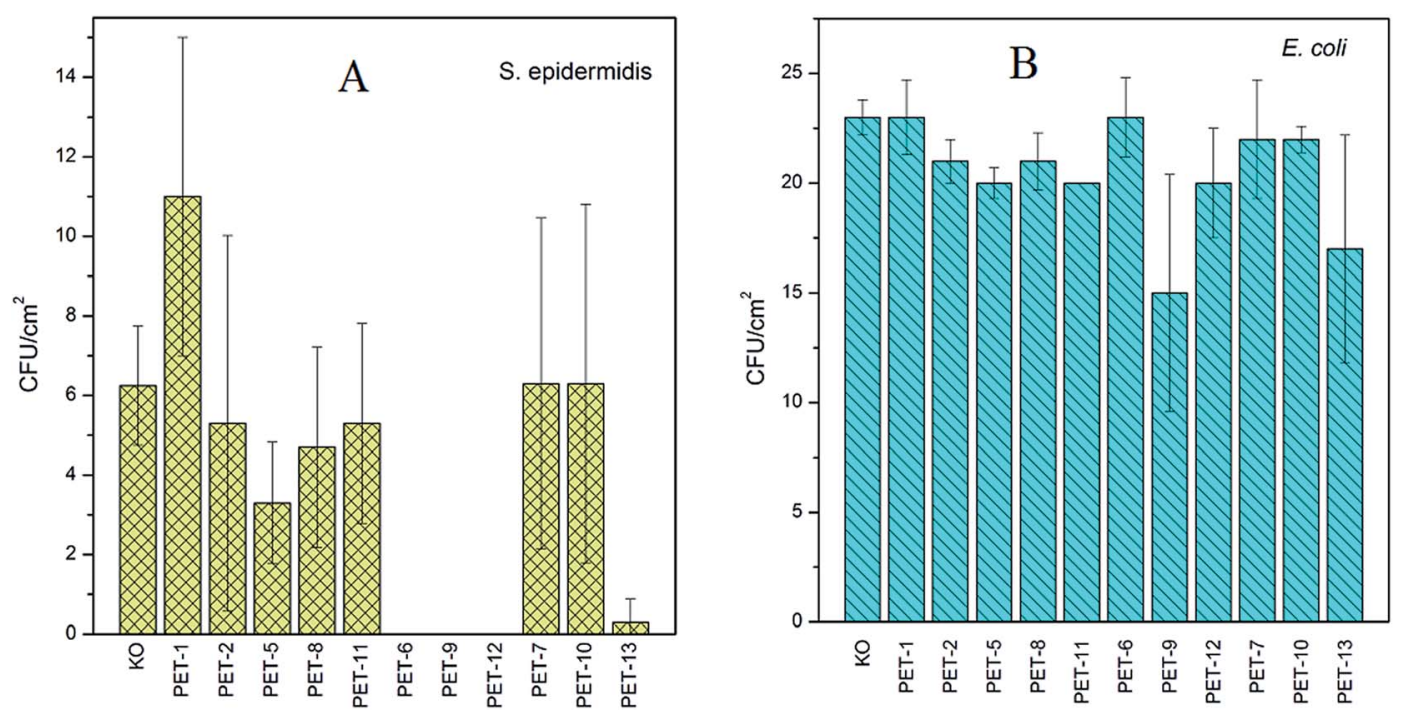

Fig. 6 The number of colonies (CFU cm ${ }^{-2}$ ) of S. epidermidis (A) and E. coli (B) on samples of pristine PET foil (PET-1) and after surface activation and chemical modification: after piranha exposure (PET-2), after subsequent grafting of the tested amino compounds (PET-5,8,11) and subsequent grafting of the tested borane compounds, B1 (PET-6,9,12) or B2 (PET-7,10,13) and their comparison with a control $(K O)$. 
that, for different polymers, the cell adhesion depends on many surface properties and the presence of amino groups on the surface may play an important role. ${ }^{16,38}$ It is known that major proteins (especially proteins in fetal bovine serum) as well as cell membranes are negatively charged under physiological $\mathrm{pH}$. The adhesion of cells on negatively charged membranes may be facilitated by electrostatic interactions and better cell adhesion may be expected on positively charged surfaces. ${ }^{16,38}$

On the other hand, molecules of the tested boranes could more easily penetrate through bacterial cells due to the absence of an outer membrane (phospholipid bilayer) in Gram-positive bacteria. $^{\mathbf{4 0}}$

The obtained results of the antibacterial tests show that the antibacterial behavior of the tested boranes is preserved even after their grafting on substrate surfaces, which originally had no antibacterial behavior.

\section{Experimental}

\section{a. Materials}

$50 \mu \mathrm{m}$ thick polyethylene terephthalate (PET) foils were supplied by GoodFellow Ltd., UK.

The surface of the PET foils was firstly activated with piranha solution for one hour. Piranha solution was prepared as a mixture of acid and hydrogen peroxide in the proportion $3: 1$. We used acetic acid $\left(\mathrm{CH}_{3} \mathrm{COOH}, 99 \%\right.$, Lachema, $\left.\check{\mathrm{CR}}\right)$ or sulfuric acid $\left(\mathrm{H}_{2} \mathrm{SO}_{4}, 96 \%\right.$, Lach:Ner, s.r.o. Neratovice) and hydrogen peroxide $\left(\mathrm{H}_{2} \mathrm{O}_{2}, 30 \%\right.$, P. A. Lach:Ner, s.r.o. Neratovice) for the preparation of the piranha solution. After one hour of exposure, the samples were taken out of the piranha solution and washed with distilled water.

The activated samples then were put into a $10 \%$ aqueous solution containing (i) cysteamine ((HS(CH) $\left.)_{2}\right)_{2} \mathrm{NH}_{2}, 98 \%$, Sigma Aldrich), (ii) ethylenediamine $\left(\mathrm{NH}_{2}\left(\mathrm{CH}_{2}\right)_{2} \mathrm{NH}_{2}\right.$, MERCK) or (iii) chitosan (85\%, deacetylated powder, Alfa Aesar). After 24 hours, the samples were rinsed with distilled water, dried and inserted into the tested solutions in dichloroethane for 24 hours. The borane compounds used in this work, anti- $\mathrm{B}_{18} \mathrm{H}_{22}$ (B1) and 4,4'(HS $)_{2}$-anti- $\mathrm{B}_{18} \mathrm{H}_{20}$ (B2), were synthesized according to a published procedure..$^{\mathbf{2 3 4}, \mathbf{4 2}}$ The chemical grafting procedure has been described previously. ${ }^{5,16,34,43}$

\section{b. Analytical methods}

Surface properties, before and after each step of activation and/ or chemical modification, were characterized using electrokinetic analysis, X-ray photoelectron spectroscopy, goniometry and UV-vis spectroscopy. Also, some antimicrobial tests on pristine and modified samples were carried out.

Electrokinetic analysis (zeta potential determination) was accomplished using the SurPASS electrokinetic analyser (Anton Par, Austria). For each measurement, a pair of polymer foils of the same sample was fixed on two sample holders $\left(2 \times 1 \mathrm{~cm}^{2}\right)$. Measurements were carried out in a cell with an adjustable gap (of about $100 \mu \mathrm{m}$ ), at room temperature, atmospheric pressure and a constant $\mathrm{pH}$ of 6.7. For the determination of zeta potential, the streaming current method and the Helmholtz-
Smoluchowski equation ${ }^{5,43,44}$ were used. The typical experimental error of the results was $5 \% .{ }^{5,43,45}$

The analysis of the surface composition was performed using XPS. The high vacuum chamber, operated at $3 \times 10^{-9} \mathrm{mbar}$, was equipped with an XR50 X-ray source (SPECS) and used an Al cathode (1486.6 eV) with a hemispherical analyzer (PHOIBOS 100, SPECS) with a 5-channel detector. The spectra were referenced to the $\mathrm{C} 1 \mathrm{~s}$ peak of aliphatic $\mathrm{C}-\mathrm{C}$ bonds at $285 \mathrm{eV} .^{\mathbf{4 6 , 4 7}}$

Surface wettability was determined by measuring the static contact angle of water, at room temperature, using the SEE system (Surface Energy Evolution System) from AdveX Instruments. A drop of distilled water with a volume of $8.0 \mu \mathrm{L}$ was applied on a surface using an automatic pipette, photographed and evaluated by the SEE system. Each surface was tested with 3 pieces of the same surface. 10 drops at different positions were dropped and analyzed on all of these pieces of the samples. All obtained values for contact angles were then statistically evaluated.

The effect of borane compound grafting on fluorescence intensity was examined using UV-vis spectroscopy. The best known and the most striking example is the absorption of the fluorescence agent in the ultraviolet region and the subsequent emitted light in the visible region. ${ }^{5,34}$

Antibacterial tests and tests on the inhibition of algae growth were performed in order to determine the antibacterial properties of the prepared composites.

The antibacterial tests were carried out by the drip method, using Escherichia coli (E. coli) and Staphylococcus epidermidis ( $S$. epidermidis). Pristine PET foil and modified PET samples were immersed in physiological saline solution. An aliquot of diluted $E$. coli or $S$. epidermidis culture was inoculated in the saline solution with the samples (a final concentration of $1.0 \times 10^{4}$ $\mathrm{CFU} \mathrm{mL} \mathrm{m}^{-1}$ for E. coli and $4.0 \times 10^{4} \mathrm{CFU} \mathrm{mL}^{-1}$ for $S$. epidermidis; $\mathrm{CFU}$ is the number of colony forming units). Bacterial samples incubated only in the pure physiological solutions served as a control. Inoculated solutions were incubated at laboratory temperature in static conditions for $2 \mathrm{~h}$. Aliquots of $25 \mu \mathrm{L}$ from all samples were placed on LB agar plates. The growth of E. coli or $S$. epidermidis was evaluated after $20 \mathrm{~h}$ of growth at $37^{\circ} \mathrm{C}$ for $S$. epidermidis and at laboratory temperature for $E$. coli. Each sample was prepared separately in triplicate. Detailed descriptions of these tests were presented earlier. ${ }^{37,39}$

Bacterial strains of environmental Gram-negative bacteria, Escherichia coli (DBM 3138), and Gram-positive bacteria, Staphylococcus epidermidis (DBM 3179), were acquired from The Microbial Type Culture Collection (Institute of Chemical Technology, Prague). The methodology of these tests has been developed at UCT Prague and the different amounts of bacteria added to the samples were determined in previous experiments. The reason for this is the different behaviour of individual bacterial colonies. ${ }^{37}$ S. epidermidis exhibits worse (slower) growth and higher sensitivity (so even less and worse proliferation) in comparison with $E$. coli. To balance the difference, a greater amount of $S$. epidermidis bacteria was added to the bacterial suspension. This procedure is always carried out in this way, so the results can be compared with previous measurements. Therefore, after finding out the OD600 (optical 
density), the suspension is diluted so that the $S$. epidermidis concentration is 2-4 times higher than that of E. coli.

An inhibition of algae growth test was carried out using a procedure based on EN ISO 8692:2012 (ref. 48) with Desmodesmus quadricauda under non-stop illumination. An algae suspension was dropped $(1.5 \mathrm{~mL})$ onto the surfaces of the pieces of sample $(3 \times 1 \mathrm{~cm})$. The concentration of algae was determined by direct counting under a microscope using a Cyrrus II chamber. The first sample was withdrawn $(\sim 0.1 \mathrm{~mL})$ one hour after suspension addition, then after 48 hours and after 168 hours. A more detailed description of this test and the preparation of the medium were presented earlier. ${ }^{49}$

\section{Conclusions}

Polyethylene terephthalate foils (PET) were activated with piranha solution and grafted with selected amino compounds (cysteamine, ethylenediamine or chitosan) and then with borane compounds. The results of the subsequent modification steps were monitored using different analytical methods. The main results can be summarized as follows;

(i) Sole piranha treatment results in activation of the PET surface, which in turn facilitates subsequent grafting with amino- and borane-compounds. Piranha treatment leads to an increase in oxygen surface concentration.

(ii) Pre-grafting of amino compounds on piranha activated polymer surfaces facilitates subsequent borane grafting and increases the amount of borane compounds embedded on the PET surface.

(iii) Modification leads to changes in surface wettability. While amino compounds can increase surface hydrophilicity, borane compounds, especially B2, can increase surface hydrophobicity.

(iv) The antibacterial tests showed that the B1 borane compound significantly improved the antimicrobial activity of the prepared composites, especially against $S$. epidermidis. The effect is further improved by pre-grafting with selected amino compounds, especially with chitosan. Only a slight antibacterial effect was observed on $E$. coli, the resistance of which against many agents is well known.

(v) PET foils, modified with amino compounds and subsequently with B1, showed clear fluorescence under UV lamp irradiation.

(vi) The present results show that boranes embedded on modified PET foils preserve their excellent physico-biological properties and PET/borane composites can have applications in different fields such as luminophore development and/or in medicine or environmental research.

\section{Conflicts of interest}

There are no conflicts of interest to declare.

\section{Acknowledgements}

This work was supported by the Grant Agency of Health Ministry under project no. 15-33018A and by the internal grant of the J. E. Purkinje University in Ústí nad Labem in the Czech Republic
(SGA project UJEP-SGS-2016-53-001-3). The authors greatly thank Dr Michael G. S. Londesborough from the Institute of Inorganic Chemistry of the Czech Academy of Sciences in Husinec-Řež for borane synthesis and providing samples for testing. The authors acknowledge assistance provided by the Research Infrastructure NanoEnviCz, supported by the Ministry of Education, Youth and Sports of the Czech Republic under Project No. LM2015073.

\section{References}

1 M. Friedman and G. Walsh, Polym. Eng. Sci., 2002, 42(8), 1756.

2 K. N. Padniyaraj, V. Selvarajan, R. R. Deshmukh and C. Cao, Vacuum, 2009, 83, 332.

3 S. Bag, V. P. Kumar and S. Maiti, J. Appl. Polym. Sci., 1999, 71, 1041.

4 M. R. Sanchis, V. Blanes, M. Blanes, D. Garcia and R. Balart, Eur. Polym. J., 2006, 42, 1558.

5 M. Benkocká, T. Knapová, J. Braborec, J. Matoušek, H. Černá, M. G. S. Londesborough, V. Švorčík and Z. Kolská, Chem. Listy, 2015, 109(12), 960.

6 Z. Kolská, M. Benkocká, T. Knapová, N. Slepičková Kasálková, K. Kolářová, P. Slepička and V. Švorčík, Manufact. Technol., 2016, vol. 16, p. 949.

7 S. Lupínková, M. Benkocká, J. Braborec, J. Matoušek, K. Kolářová, M. G. S. Londesborough and Z. Kolská, Czech. Chem. Soc. Symp. Ser., 2016, vol. 14, p. 19.

$8 \mathrm{~J}$. Behnisch, A. Hollander and H. Zimmermann, J. Appl. Polym. Sci., 1993, 49, 117.

9 S. Bhowmik, P. K. Ghosh, S. Ray and S. K. Barthwal, J. Adhes. Sci. Technol., 1998, 12, 1181.

10 V. Kotál, V. Švorčík, P. Slepička, O. Bláhová, P. Šutta and V. Hnatowicz, Plasma Processes Polym., 2007, 4, 69.

11 S. Guruvenket, G. M. Rao, M. Komath and A. M. Raichur, Appl. Surf. Sci., 2004, 236, 278.

12 J. Shin, X. Liu, N. Chikthimmah and Y. S. Lee, Appl. Surf. Sci., 2016, 386, 276.

13 M. Razavizadeh and M. Jamshidi, Appl. Surf. Sci., 2016, 379, 114.

14 B. Kordoghli, R. Khiari, M. F. Mhenni, F. Sakli and M. H. Belgacem, Appl. Surf. Sci., 2012, 258, 9737.

15 L. Bačáková and V. Švorčík, Cell Growth Processes: New Research, ed. D. Kimura, Nova Science Publishers, Inc., Hauppauge, New York, 2008, p. 5.

16 Z. Kolská, A. Řezníčková, M. Nagyová, N. Slepičková Kasálková, P. Sajdl, P. Slepička and V. Švorčík, Polym. Degrad. Stab., 2014, 101, 1.

17 J. M. Goddard and J. H. Hotchkiss, Prog. Polym. Sci., 2007, 32, 698.

18 J. A. Barish and J. M. Goddard, J. Appl. Polym. Sci., 2011, 120, 2863.

19 R. C. Chatelier, X. Xie, T. R. Gengenbach and H. J. Griesser, Langmuir, 1995, 11, 2576.

20 B. Jansen and W. Kohnen, J. Ind. Microbiol., 1995, 15, 391.

21 T. Sato, K. Hiruma, M. Shirai, K. Tominanga, K. Haraguchi, T. Katsuyama and T. Shimada, Appl. Phys. Lett., 1995, 66, 159. 
22 M. G. S. Londesborough, D. Hnyk, J. Bould, L. SerranoAndrés, V. Saurí, J. M. Oliva, P. Kubát, T. Polívka and K. Lang, Inorg. Chem., 2012, 51, 1471.

23 V. Saurí, J. M. Oliva, D. Hnyk, J. Bould, J. Braborec, M. Merchán, P. Kubát, I. Císařová, K. Lang and M. G. S. Londesborough, Inorg. Chem., 2013, 52, 9266.

24 M. Derosa and R. J. Crutchley, Coord. Chem. Rev., 2002, 233, 351.

25 K. Lang, J. Mosinger and D. M. Wagnerová, Coord. Chem. Rev., 2004, 248, 321.

26 Y. N. Konan, R. Gurny and E. Allémann, J. Photochem. Photobiol., B, 2002, 66, 89.

27 M. Paskevicius, B. Hansen, M. Jorgensen, B. Richter and T. R. Jensen, Nat. Commun., 2017, 8, 15136.

28 E. Kvasničková, J. Masak, J. Cejka, O. Matatkova and V. Sicha, J. Organomet. Chem., 2017, 827, 23.

29 J. R. Lakowicz, Principles of fluorescence spectroscopy, Springer, New York, 3rd edn, ch. XXVI, 2006, p. 954.

30 D. C. Harris, Exploring chemical analysis, W. H. Freeman, New York, 3rd edn, ch. XIII, 2005, p. 610.

31 T. Kawai, T. Sasaki and M. Irie, Chem. Commun., 2001, 8, 711. 32 N. Singh, H. K. Patel, S. K. Dixit and H. S. Vora, J. Lumin., 2013, 134, 607.

33 V. Shkolnikov, J. G. Santiago, M. A. Quesada, R. A. Mathies and A. N. Glazer, Lab Chip, 2013, 13, 1632.

34 Z. Kolská, J. Matoušek, P. Čapková, J. Braborec, H. Černá, M. Benkocká and M. G. S. Londesborough, Appl. Clay Sci., 2015, 118, 295.

35 P. Slepička, N. Slepičková Kasálková, L. Bačáková, Z. Kolská and V. Švorčík, J. Nanomater., 2012, 17.
36 N. Slepičková Kasálková, P. Slepička, Z. Kolská, P. Hodačová, Š. Kučková and V. Švorčík, Nanoscale Res. Lett., 2014, 9, 161. 37 V. Vosmanská, K. Kolářová, S. Rimpelová, Z. Kolská and V. Švorčík, RSC Adv., 2015, 23(5), 17690.

38 N. Faucheux, R. Schweiss, K. Lutzow, C. Werner and T. Groth, Biomaterials, 2004, 25, 2721.

39 K. Kolářová, V. Vosmanská, S. Rimpelová, P. Ulbrich and V. Švorčík, J. Nanosci. Nanotechnol., 2015, 15(12), 10120.

40 M. Polívková, J. Siegel, K. Kolářová, S. Rimpelová and V. Švorčík, Chem. Listy, 2016, 110, 139.

41 A. R. Pitochelli and M. F. Hawthorne, J. Am. Chem. Soc., 1962, 84, 3218.

42 Y. Li and L. G. Sneddon, Inorg. Chem., 2005, 45, 470.

43 Z. Kolská, A. Řezníčková and V. Švorčík, e-Polym., 2012, 13.

44 Z. Kolská, Z. Makajová, K. Kolářová, N. Kasálková Slepičková, S. Trostová, A. ̌̌ezníčková, J. Siegel and V. Švorčík, Polymer Science, ed F. Yılmaz, InTech d.o.o., Rijeka, Croatia, 2013, p. 203.

45 Z. Kolská, N. Slepičková Kasálková, J. Siegel and V. Švorčík, J. Nano Res., 2013, 25, 31.

46 M. Barchuk, P. Čapková, Z. Kolská, J. Matoušek, D. Poustka, L. Šplíchalová, O. Benada and M. Munzarová, J. Polym. Res., 2016, 23, 20.

47 M. Benkocká, K. Kolářová, J. Matoušek, A. Semerádtová, V. Šícha and Z. Kolská, Appl. Surf. Sci., 2018, 441, 120.

48 EN ISO 8692:2012, Water quality - Fresh water algal growth inhibition test with unicellular green algae.

49 J. Říhová Ambrožová and J. Trögl, Standardní postupy environmentální mikrobiologie, J. E. Purkyně University, Faculty of Environment, 2014, ISBN 978-80-7414-854-5 online pdf. 